\title{
ANÁLISE MORFOLÓGICA DE ESPÉCIES DA ARBORIZAÇÂO DE RUAS DE CURITIBA-PR E A INFESTAÇÃO POR ERVA-DE-PASSARINHO
}

\author{
Cristina Sulevis ${ }^{1}$, Daniela Biondi ${ }^{2}$
}

\section{RESUMO}

O objetivo geral deste trabalho foi avaliar a infestação das árvores de ruas por ervas-depassarinho e analisar as características morfológicas arbóreas. A pesquisa foi desenvolvida em uma amostragem da arborização de ruas em 6 bairros na cidade de Curitiba-PR. Além da percentagem de ocorrência de erva-de-passarinho nas árvores de ruas, foram analisadas as características morfológicas das espécies arbóreas com maior ou nenhuma ocorrência da mesma. Nas 1926 árvores das 6 amostras analisadas, 25,8\% apresentaram infestação com erva-de-passarinho. Lagerstroemia indica L. e Tipuana tipu (Benth.) Kuntze foram as espécies que apresentaram maior ocorrência de erva-de-passarinho com 22,5\% e 20,9\% do total de indivíduos infestados. Nenhuma ocorrência de ervas-de-passarinho foi verificada em Handroanthus chrysotrichus (Mart. ex A.DC.) Mattos e Lafoensia pacari A. St.-Hil. Das quatro espécies analisadas, $50 \%$ são exóticas; $75 \%$ são de casca áspera; $75 \%$ são caducifólias; $75 \%$ são de copa globosa e densifoliada e 100\% são de médio a grande porte. Verificou-se que as características como superfície de casca, hábito, forma e densidade da copa e altura não diferem entre ás árvores susceptíveis ou não ao parasitismo. A característica densidade da madeira pode representar um fator limitante à ocorrência de erva-de-passarinho, porém há a necessidade de estudos mais aprofundados.

Palavras-chave: Hemiparasita; Tipuana; Extremosa; Dedaleiro; Densidade da madeira. 


\title{
MORPHOLOGICAL ANALYSIS OF SPECIES OF THE URBAN STREET TREES IN THE CITY OF CURITIBA-PR AND THE INFESTATION BY MISTLETOES
}

\begin{abstract}
The aim of this study was to evaluate of infestation on urban street trees by mistetloe and analyze the morphological characteristics of trees. The study was conducted in six samples. In addition to the percentage of occurrence of mistetloe in the urban streets trees, were also analyzed the morphologicalcharacteristics of tree species with higher or no occurrence of the same. In 1926 trees of six samples analyzed, 25.8\% were infested with mistetloe. Lagerstroemia indica L. and Tipuana Tipu (Benth.) Kuntze were species that had increased incidence of mistetloe with $22.5 \%$ and $20.9 \%$ of infested individuals. No occurrence of mistetloe was found in Handroanthus chrysotrichus (Mart. ex A.DC.) Mattos and Lafoensia pacari A.St.-Hil.. Of the four species analyzed, $50 \%$ are exotic and $75 \%$ are of rough bark, $75 \%$ are deciduous, $75 \%$ are and globular crown densifoliada and $100 \%$ are medium to large. It was found that the surface characteristics such as bark, habit, shape and density of the crown and height did not differ among the trees or not susceptible to parasitism. The wood density may represent a limiting factor to the occurrence of mistletoe, but there is a need for further studies.
\end{abstract}

Keywords: Mistletoe; Tipuana; Extremosa; Dedaleiro; Density of the wood.

\section{INTRODUÇÃO}

Erva-de-passarinho é o nome popularmente empregado para designar as plantas pertencentes à família Loranthaceae (ROTTA, 2001). Os frutos da erva-de-passarinho são consumidos pelas aves, consideradas os principais agentes de dispersão das suas sementes (CAZETTA; GALETTI, 2003).

Das 300 mil árvores plantadas nas vias públicas dessa cidade, segundo estimativas da Secretaria Municipal do Meio Ambiente, em aproximadamente 30\% ocorre a erva-depassarinho (MOTTA, 1995; ZILIOTTO et al. 1999; ROTTA, 2001). 
As ervas-de-passarinho parasitam árvores, arvoretas, e arbustos. São plantas perenes, com folhas sempre verdes, fixam-se nos galhos e caule da planta hospedeira emitindo suas raízes especiais, chamadas de haustórios, através das quais sugam os elementos vitais para seu crescimento, não necessitando, portanto do contato com o solo. As ervas-de-passarinho são consideradas hemiparasitas, pois realizam fotossíntese permitindo metabolizar substancias orgânicas para o seu desenvolvimento (TATTAR, 1978; ROTTA, 2006).

Algumas ervas-de-passarinho são generalistas, podendo parasitar uma variedade de hospedeiros, enquanto que outras apresentam uma limitação na quantidade de hospedeiros que parasitam, sendo que algumas poucas espécies são conhecidas por parasitarem apenas uma única espécie de plantas (NORTON; CARPENTER, 1998; CAZETTA; GALETTI, 2003) e são chamadas também de especialistas.

A infestação pela erva-de-passarinho pode ser considerada um fator relevante a ser monitorado, pois, se em desequilíbrio, compromete todo um programa de arborização (ROTTA, 2001). Dentre os efeitos que elas causam nas plantas hospedeiras pode-se destacar a redução do vigor e da produção de frutos e sementes, mau funcionamento dos tecidos lenhosos, produção de galhas, folhagem esparsa, morte do ápice, predisposição ao ataque de insetos e doenças e, até mesmo, morte prematura (HARRIS, 1992).

Muitos estudos foram realizados a fim de correlacionar as ervas-de-passarinho e seus hospedeiros, porém até o momento as pesquisas realizadas não foram conclusivas quanto à relação parasita-hospedeiro.

Uma mesma espécie de árvore pode apresentar infestação por erva-de-passarinho em determinada região, contudo, em outras pode apresentar pouca ou nenhuma infestação. Até mesmo espécies de outras regiões, como as espécies exóticas não estão imunes ao parasitismo. Pesquisas realizadas por Rotta, (2006) e White et al. (2010), mostraram que as árvores exóticas são mais susceptíveis a infestação por erva-de-passarinho que as árvores nativas.

Segundo Motta (1995), o fato de a arborização urbana ser constituída por um número reduzido de espécies e sua distribuição espacial ocorrerem de tal maneira que, indivíduos da mesma espécie possam compor a arborização de toda uma rua, facilita a infestação por pragas e doenças. Isto diferente do que ocorre em florestas nativas, onde a presença das ervas-de-passarinho não apresenta problema sério devido a grande diversidade de espécies.

Segundo o levantamento realizado por Motta (1995), as espécies que apresentavam problemas com infestação por erva-de-passarinho eram: Lagerstroemia Indica (extremosa), 
Ligustrum japonicum (alfeneiro), Acer negundo (acer), Tipuana tipu (tipuana), Schinus terebentifolius (aroeira) e Melia azedarach (cinamomo).

Os estudos realizados por Leal et al. (2006) constataram a presença de erva-depassarinho em 28,19\% das 1926 árvores amostradas na cidade de Curitiba-PR. As árvores infestadas foram: Acer negundo, Lagerstroemia indica, Ligustrum lucidum, Melia azedarach, Handroanthus chrysotrichus e Tipuana tipu, sendo L. lucidum e T. tipu as espécies mais infestadas. Rotta (2001) observou em seu estudo que aproximadamente $14 \%$ da vegetação do Passeio Público de Curitiba, encontravam-se infestada por erva-de-passarinho, sendo que destas, $67 \%$ são exóticas.

White et al. (2010) analisando a ocorrência de erva-de-passarinho na arborização da Universidade Federal de Sergipe, Campus São Cristóvão constataram a presença de ervade-passarinho em $8,15 \%$ das árvores. A infestação ocorreu em quatro plantas exóticas Azadirachta indica A. Juss., Casuarina equisetifolia Linn., Pithecellobium dulce (Roxb.) Benth e Terminalia catappa Linn. - e em apenas uma planta nativa - Anacardium occidentale Linn.. Matos et al. (2009) em um estudo realizado no bairro Centro da cidade de Aracaju, Sergipe, constatou infestação em 7,5\% das árvores analisadas. Ruschel; Leite (2002), na arborização urbana no centro da cidade de Lajeado (RS), observou infestação em 9,40\% das árvores. Arruda (2004) observou a espécie Struthanthus aff. polyanthus infestando $17,7 \%$ das árvores de uma área do Cerrado, em Uberlândia-MG.

O objetivo geral deste trabalho foi avaliar o grau de infestação das árvores de ruas por ervas-de-passarinho e analisar as características morfológicas das árvores infestadas. E teve como objetivo específico, definir um conjunto de características morfológicas que pudessem ser relacionadas com a susceptibilidade da árvore à infestação por erva-depassarinho.

\section{MATERIAIS E MÉTODOS}

A pesquisa foi desenvolvida na cidade de Curitiba-PR (Figura 1), mais especificamente em seis unidades amostrais de ruas arborizadas, localizadas nos bairros Água Verde, Portão, Seminário, Mercês, Bigorrilho e Rebouças (Figura 2). A seleção das amostras foi de forma aleatória tomando como base as 15 unidades amostrais analisadas no inventário da arborização de ruas de Curitiba realizado por Milano (1984), o qual utilizou uma amostragem aleatória simples com parcelas fixas de 500 m x 500 m. Sendo assim, 
o número de unidades amostrais utilizadas nesta pesquisa representa 40\% (6 unidades) deste levantamento realizado anteriormente.

Figura 1. Localização geográfica da cidade de Curitiba

Figure 1. Geographical location of the city of Curitiba
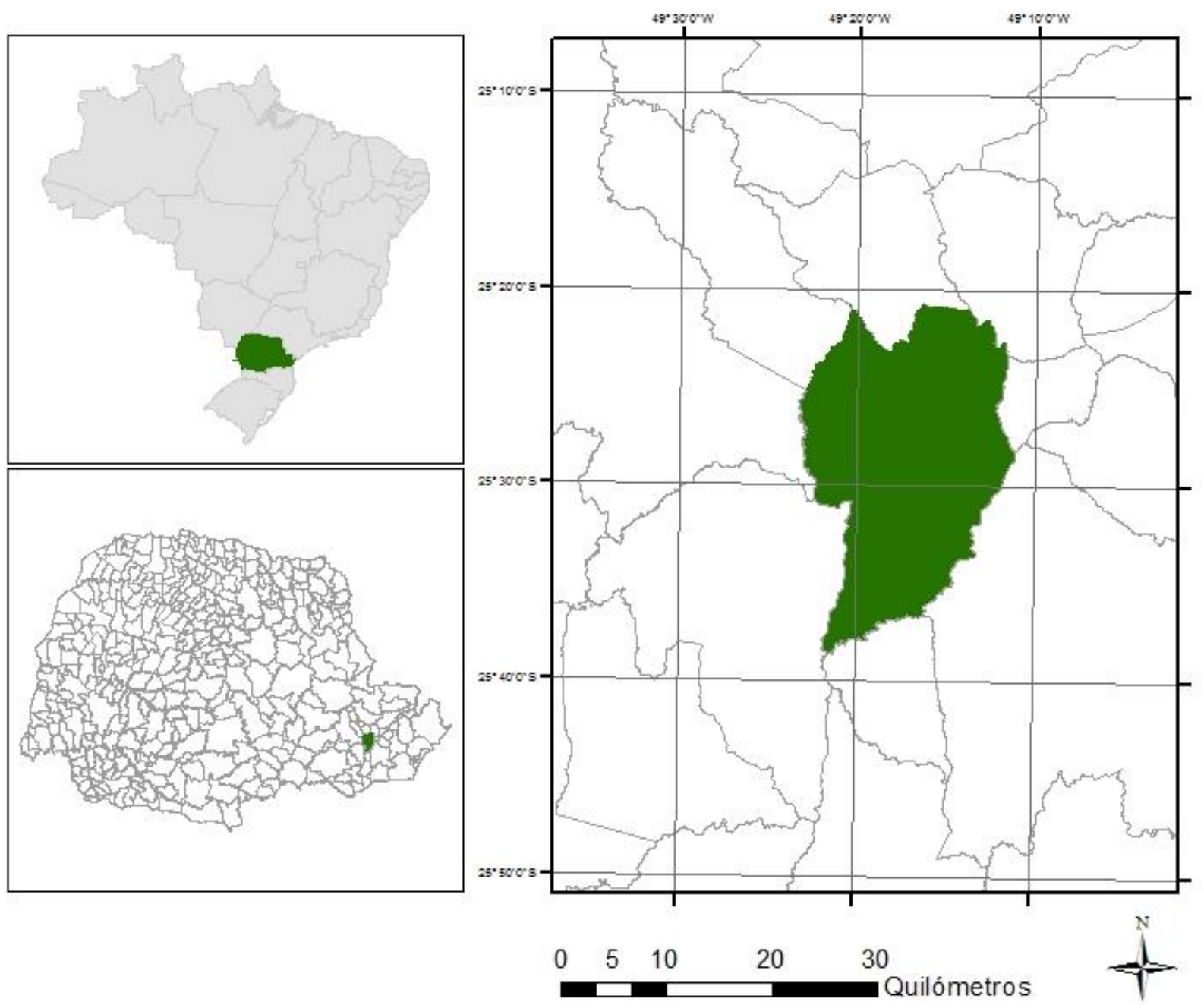
Figura 2. Bairros de Curitiba nos quais se encontram as unidades amostrais

Figure 2. Neighborhoods of Curitiba where are the sampling units

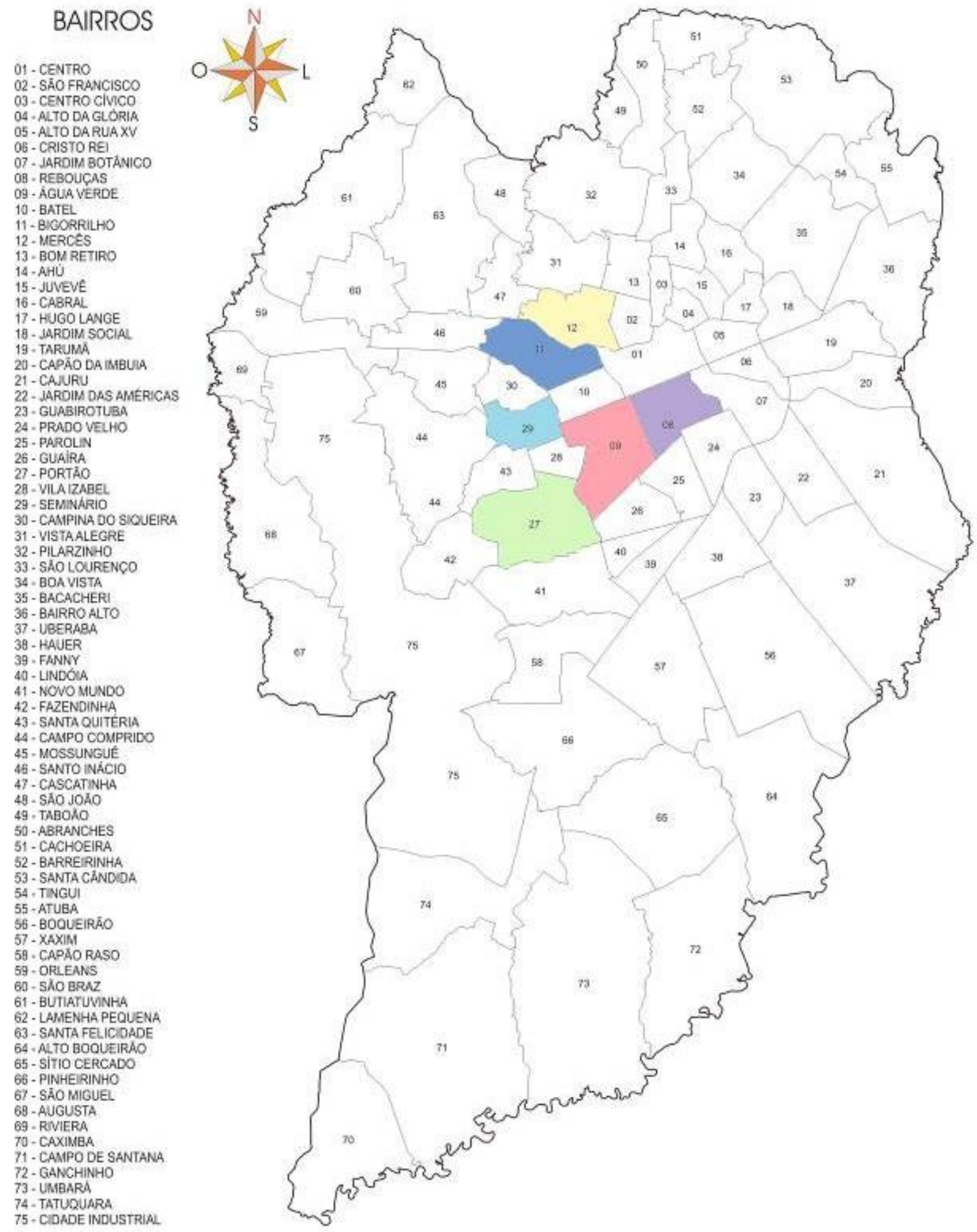

Fonte: IPPUC, 2006 
Através de um levantamento de campo foram coletadas e identificadas todas as espécies das unidades amostrais, e verificada a presença ou não de erva-de-passarinho.

Os dados obtidos foram processados em planilha Excel, na qual foram agrupadas e identificando as dez espécies mais representativas na arborização dessas 6 amostras. As variáveis analisadas foram: a percentagem de ocorrência de erva-de-passarinho nas árvores de ruas e as características das espécies arbóreas com maior ou nenhuma ocorrência da mesma. Por meio de consulta em bibliografias especializadas, tais como: Mainieril e Chimelo (1989), Lorenzi (1992, 2000), Lorenzi et al. (2003), Backes e Irgang (2004); Carvalho $(2003,2006)$, foram analisadas as seguintes características morfológicas das árvores selecionadas:

a) Procedência da espécie - nativa ou exótica;

b) Superfície da casca morta - áspera ou lisa;

c) Hábito - caducifólia ou perenifólia;

d) Forma e densidade de copa - globosa, umbeliforme ou elíptica, e aberta ou densifoliada;

e) Altura - pequeno porte $(<6 m)$, médio porte $(6 m-12 m)$, grande porte $(>12 m)$;

f) Densidade da madeira - baixa $\left(<5 \mathrm{~g} / \mathrm{cm}^{3}\right)$, média $\left(5-7 \mathrm{~g} / \mathrm{cm}^{3}\right)$, alta $\left(0,7-1,0 \mathrm{~g} / \mathrm{cm}^{3}\right)$, e muito alta $\left(>1,0 \mathrm{~g} / \mathrm{cm}^{3}\right)$.

\section{RESULTADOS E DISCUSSÃO}

\section{Análise da percentagem de infestação}

Foram encontradas 1926 árvores nas seis unidades amostrais, pertencentes a 79 espécies. Do total, 497 árvores (25,8\%) apresentaram infestação por erva-de-passarinho. Tipuana tipu (Benth.) O. Kuntze, Acer negundo L., Ligustrum lucidum W.T. Aiton, Lagerstroemia indica L., Handroanthus albus (Cham.) Mattos e Cassia leptophylla Vog., apresentaram algum grau de infestação por erva-de-passarinho; enquanto, Handroanthus chrysotrichus (Mart. ex A.DC.) Mattos, Lafoensia pacari A. St.-Hil, Poincianella pluviosa var. peltophoroides (Benth.) L.P.Queiroz, Libidibia ferrea var. leiostachya (Benth.) L.P.Queiroz não apresentaram infestação (Tabela 1). 
Tabela 1. Total de indivíduos amostrados por espécie e a percentagem de infestação por erva-de-passarinho

Table 1. Total amount of sampled per species and the percentage mistletoe infested

\begin{tabular}{lccc}
\hline \multicolumn{4}{c}{ Ocorrência de erva-de-passarinho } \\
\hline Espécie & Total & $\begin{array}{c}\text { No de indivíduos } \\
\text { infestados }\end{array}$ & $\begin{array}{c}\text { \% de indivíduos } \\
\text { infestados }\end{array}$ \\
\hline Tipuana tipu (Benth.) O. Kuntze & 147 & 104 & 71 \\
Acer negundo L. & 70 & 35 & 50 \\
Ligustrum lucidum W.T. Aiton & 396 & 195 & 49 \\
Lagerstroemia indica L. & 465 & 112 & 24 \\
Handroanthus albus (Cham.) Mattos & 55 & 6 & 11 \\
Cassia leptophylla Vog. & 101 & 8 & 8 \\
Handroanthus chrysotrichus (Mart. ex & 76 & 0 & 0 \\
A.DC.) Mattos & 70 & 0 & 0 \\
$\begin{array}{l}\text { Lafoensia pacari A. St.-Hil } \\
\text { Poincianella pluviosa var. peltophoroides }\end{array}$ & 47 & 0 & 0 \\
(Benth.) L.P.Queiroz & & & 0 \\
Libidibia ferrea var. leiostachya (Benth.) & & 0 & \\
L.P.Queiroz & 45 & &
\end{tabular}

Os resultados obtidos nesta pesquisa são semelhantes aos resultados encontrados por Leal et al. (2006) que verificaram a ocorrência de erva-de-passarinho nas espécies citadas acima, exceto na espécie Cassia leptophylla Vog. e Handroanthus albus (Cham.) Mattos. Os mesmos autores verificaram a ocorrência de erva-de-passarinho em Handroanthus chrysotrichus (Mart. ex A.DC.) Mattos, o que não foi verificado neste estudo.

Em Lajeado, Ruschel e Leite (2002) constataram que $H$. chrysotrichus foi a espécie com maior número de hemi-parasitas e com o grau mais alto de infestação. Já T. tipu, com alta percentagem de infestação neste levantamento, não foi observada por Oliveira; Kappel (1994) em Porto Alegre.

Lafoensia pacari A. St.-Hil não apresentou nenhuma infestação, porém, Rotta (2001) encontrou $14 \%$ de infestação nas árvores analisadas no Passeio Público de Curitiba. Este fato pode estar correlacionado a distribuição espacial nos dois ambientes, no caso do Passeio Público, as árvores estão plantadas em uma área verde, que é um espaço onde as árvores estão mais próximas uma das outras que facilita a disseminação do parasita. Além disso, numa área verde existem mais atrativos para a visita dos pássaros (disseminadores das ervas-de-passarinho), como lâmina d'água e outros tipos de vegetação.

A média da percentagem de infestação de L. lucidum, T. tipu, e L. indica foram respectivamente, $56,1 \%, 45,8 \%$ e $33,0 \%$ (Tabela 2 ), diferente do observado por Leal et al. (2006), que foi de 49,92\%, 47,70\% e $21,97 \%$ e por Hemlinger et al. (2002) , que foi de $33 \%$, $21 \%$ e $13 \%$ respectivamente. 
Tabela 2. Percentagem de infestação por espécie nas seis unidades amostrais

Table 2. Percentage of infestation by species in the six sample units

\begin{tabular}{lrrrrrrrr}
\hline \multirow{2}{*}{ Espécie } & \multicolumn{8}{c}{ Amostras } \\
\cline { 2 - 10 } & $\begin{array}{l}\text { Portão } \\
(\%)\end{array}$ & $\begin{array}{c}\text { Mercês } \\
(\%)\end{array}$ & $\begin{array}{c}\text { Bigorrilho } \\
(\%)\end{array}$ & $\begin{array}{c}\text { Seminário } \\
(\%)\end{array}$ & $\begin{array}{c}\text { Água Verde } \\
(\%)\end{array}$ & $\begin{array}{c}\text { Rebouças } \\
(\%)\end{array}$ & $\begin{array}{c}\text { Média } \\
(\%)\end{array}$ \\
\hline $\begin{array}{l}\text { Tipuana tipu (Benth.) O. } \\
\text { Kuntze }\end{array}$ & 91,5 & 30,8 & 58,7 & - & 93,8 & - & 68,7 \\
Ligustrum lucidumW.T. & 100,0 & 40,7 & 9,1 & 58,3 & 49,7 & 78,7 & 56,1 \\
Aiton & 83,3 & 33,3 & 17,3 & 20,0 & 14,3 & 30,0 & 33,0 \\
Lagerstroemia indica L. & 72,4 & 0,0 & 33,3 & 0,0 & 33,3 & 50,0 & 31,5 \\
$\begin{array}{l}\text { Acer negundo L. } \\
\text { Cassia leptophylla Vog. }\end{array}$ & 3,3 & - & - & 0,0 & 0,0 & 26,1 & 7,4 \\
$\begin{array}{l}\text { Handroanthus albus } \\
\text { (Cham.) Mattos }\end{array}$ & 0,0 & 0,0 & 0,0 & 14,3 & 0,0 & 0,0 & 2,4 \\
\hline
\end{tabular}

Das 10 espécies mais plantadas nas seis amostras, Tipuana tipu (Benth.) Kuntze (Figura 3), Ligustrum lucidum W.T. Aiton, e Lagerstroemia indica L. (Figura 4) foram as espécies que apresentaram as maiores médias de infestação por erva-de-passarinho, com $68,7 \%, 56,1 \%$ e $33 \%$ respectivamente (Tabela 2 ).

A amostra que apresentou maior percentagem de infestação foi a do Portão (Tabela 3), com $43 \%$ de infestação. Isto foi devido a arborização desta amostra ser composta predominantemente pelas espécies $C$. leptophylla, $T$. tipu, e $A$. negundo, hospedeiras potenciais de erva-de-passarinho. O bairro Seminário foi a amostra com menor percentagem de infestação, com $15 \%$.

Tabela 3. Número total de indivíduos amostrados e infestados por erva-de-passarinho nas seis unidades amostrais

Table 3. Total number of individuals sampled and mistletoe infested in the six sample units

\begin{tabular}{lcccccc}
\hline Amostra & Portão & Rebouças & Água Verde & Mercês & Bigorrilho & Seminário \\
\hline Total de Árvores & 200 & 351 & 483 & 293 & 349 & 250 \\
Indivíduos Infestados & 86 & 111 & 125 & 77 & 60 & 38 \\
$\%$ de infestação & 43 & 32 & 26 & 26 & 17 & 15 \\
\hline
\end{tabular}


Figura 3. Lagerstroemia indica L. infestada por erva-de-passarinho

Figure 3. Lagerstroemia indica L. infested mistetloe
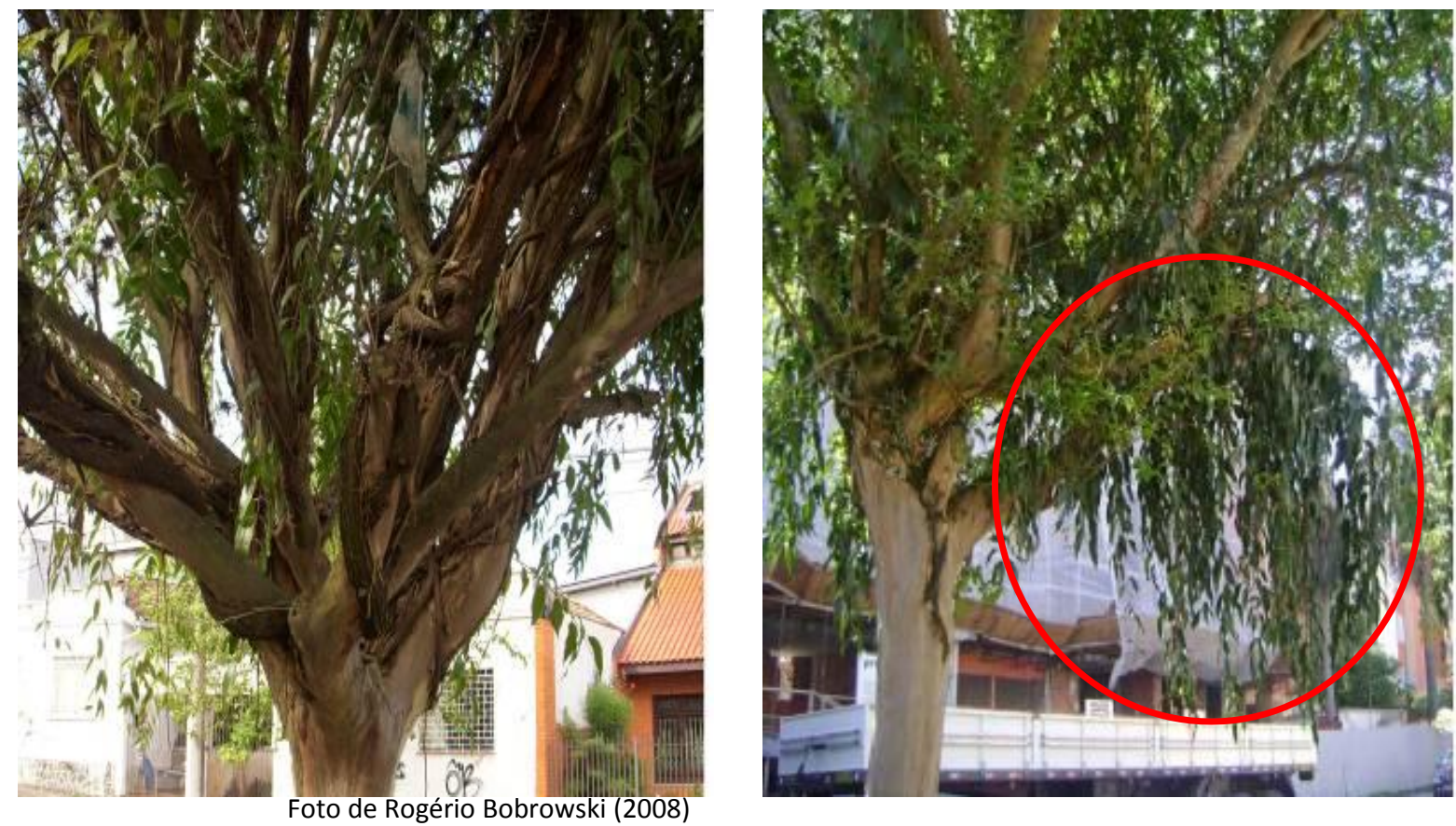

Figura 4. Tipuana tipu (Benth.) O. Kuntze infestada por erva-de-passarinho

Figure 4. Tipuana tipu (Benth.) O. Kuntze infested mistetloe
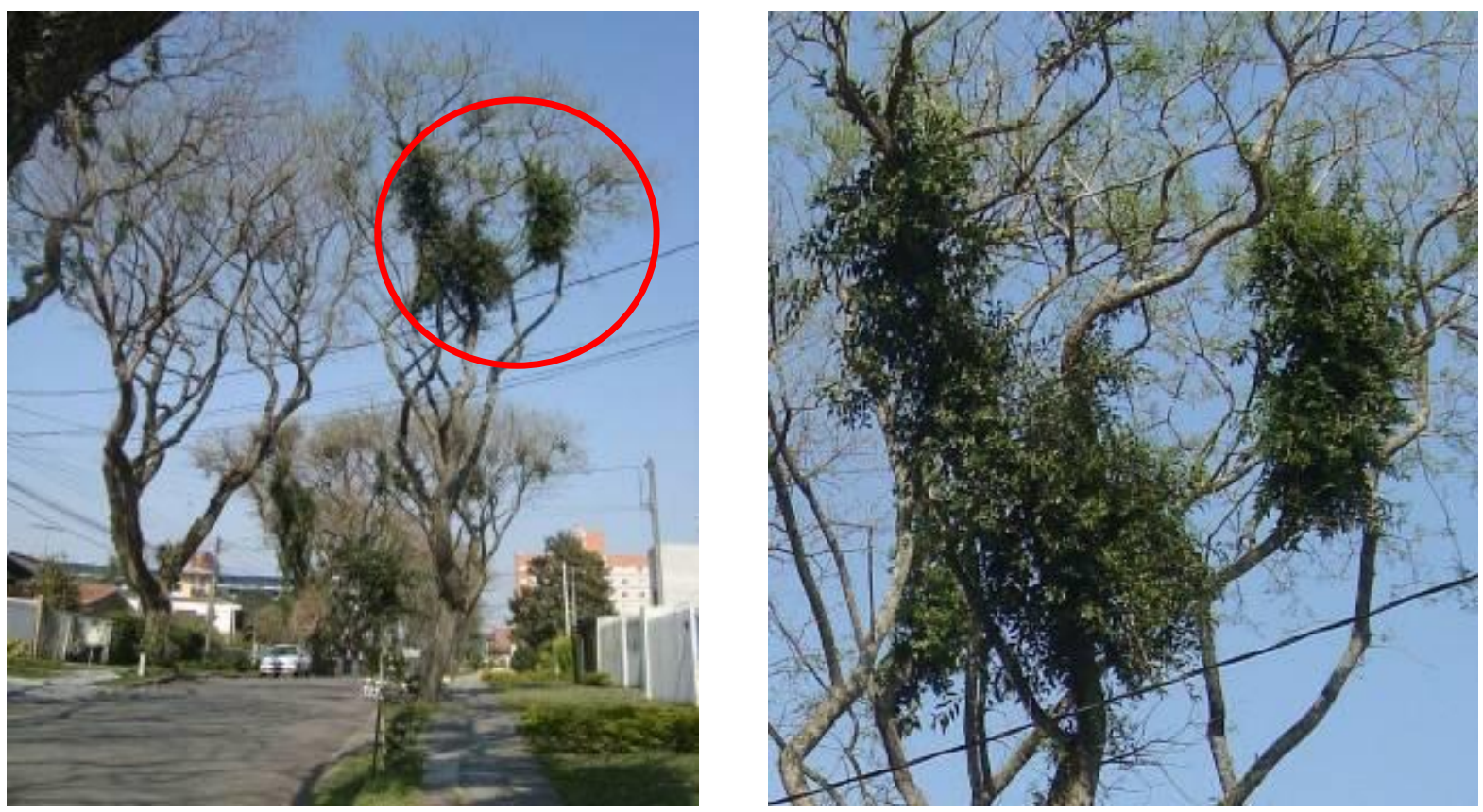


\section{Características morfológicas}

A partir da análise da percentagem de infestação foram definidas as espécies com maior percentagem de infestação a partir da tabela 2, sendo estas a espécie L. lucidum, $T$. tipu e L. indica. Não se procedeu a análise das características morfológicas do L. lucidum, pois o mesmo não é mais utilizado na arborização de ruas de Curitiba (BIONDI; ALTHAUS, 2005), por ser considerada uma espécie exótica invasora, instituído pelo Decreto Municipal $n^{\circ}$ 473/200 de 29 de Março de 2008, que "Estabelece a Lista Oficial de Espécies Florestais Exóticas Invasoras para o Município de Curitiba", e pela Portaria IAP n074, DE 19 de abril de 2007, que "Reconhece a Lista Oficial de Espécies Exóticas Invasoras para o Estado do Paraná, estabelece normas de controle e dá outras providências."

$H$. chrysotrichus e L. pacari, foram as espécies escolhidas para a análise morfológica por não apresentarem infestação por erva-de-passarinho nas amostras analisadas, e por possuírem maior número de indivíduos plantados que as espécies $P$. pluviosa e $L$. ferrea, observado na tabela 1.

\section{Tipuana tipu (Benth.) O. Kuntze}

A tipuana é uma espécie exótica, originária da Bolívia e norte da Argentina. É uma árvore de grande porte podendo alcançar 15 metros de altura (LORENZI et al., 2003). Possui hábito caducifólio, sua copa é globosa e densifoliada (Figura 5). A superfície da casca é áspera e a densidade da madeira é de 0,63 g/ $\mathrm{cm}^{3}$ (MAINIERI; CHIMELO, 1989; BACKES; IRGANG, 2004).

Figura 5. Detalhe do tronco, hábito e copa

Figure 5. Detail of the trunk, habit and canopy
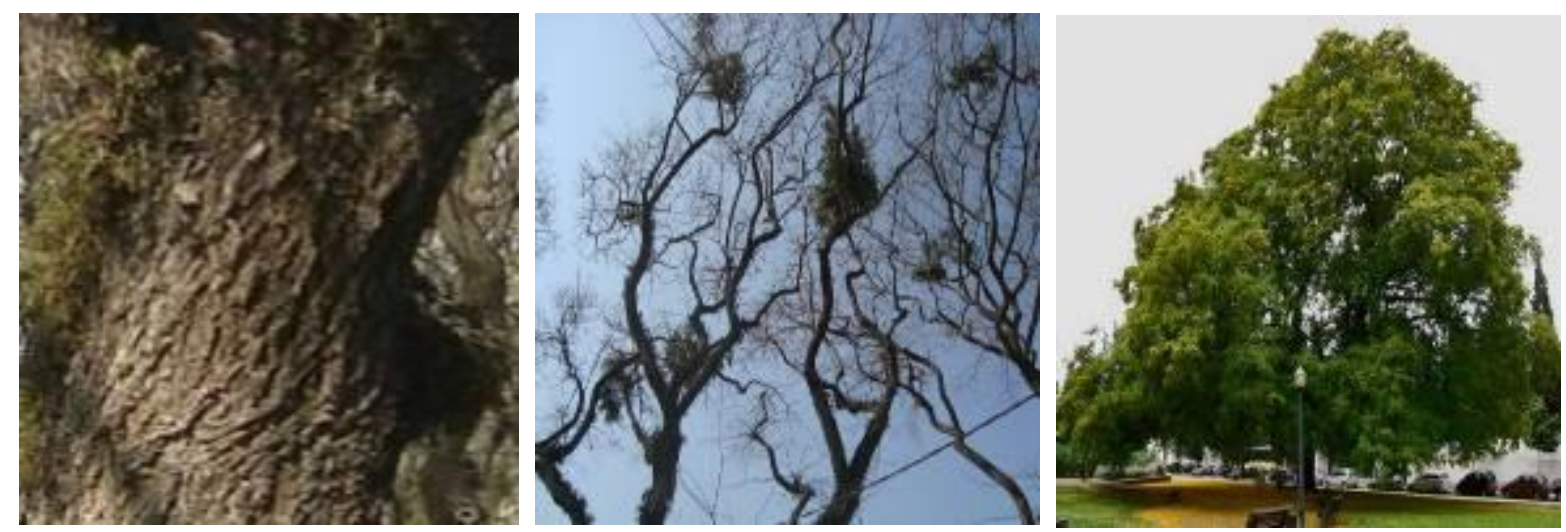


\section{Lagerstroemia indica L.}

A extremosa é uma espécie exótica, originária da Ásia e Oceania. É uma árvore de médio porte podendo atingir 7 metros de altura. Possui hábito caducifólio, sua copa é globosa e aberta (Figura 6). A superfície da casca é lisa e a densidade da madeira de extremosa é de $0,59 \mathrm{~g} / \mathrm{cm}^{3}$ (LORENZI et al., 2003; BACKES; IRGANG, 2004).

Figura 6. Detalhe do tronco, hábito e copa

Figure 6. Detail of the trunk, habit and canopy
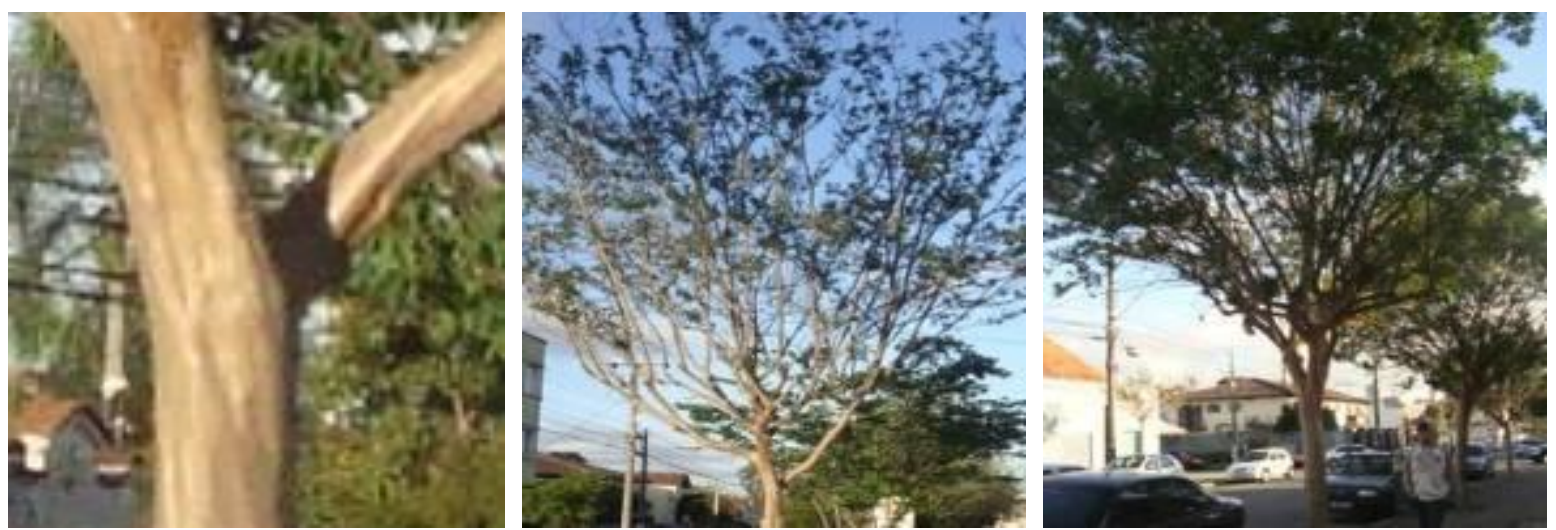

\section{Handroanthus chrysotrichus (Mart. ex A.DC.) Mattos}

O ipê-amarelo-miúdo é uma espécie nativa, de grande porte podendo alcançar 10 metros de altura. Possui hábito caducifólio, sua copa é globosa e densa (Figura 7), e superfície da casca é áspera (LORENZI,1992; 2000). A densidade da madeira do ipêamarelo-miúdo é de 1,05 g/cm³ (CARVALHO, 2006).

Figura 7. Detalhe do tronco, hábito e copa

Figure 7. Detail of the trunk, habit and canopy
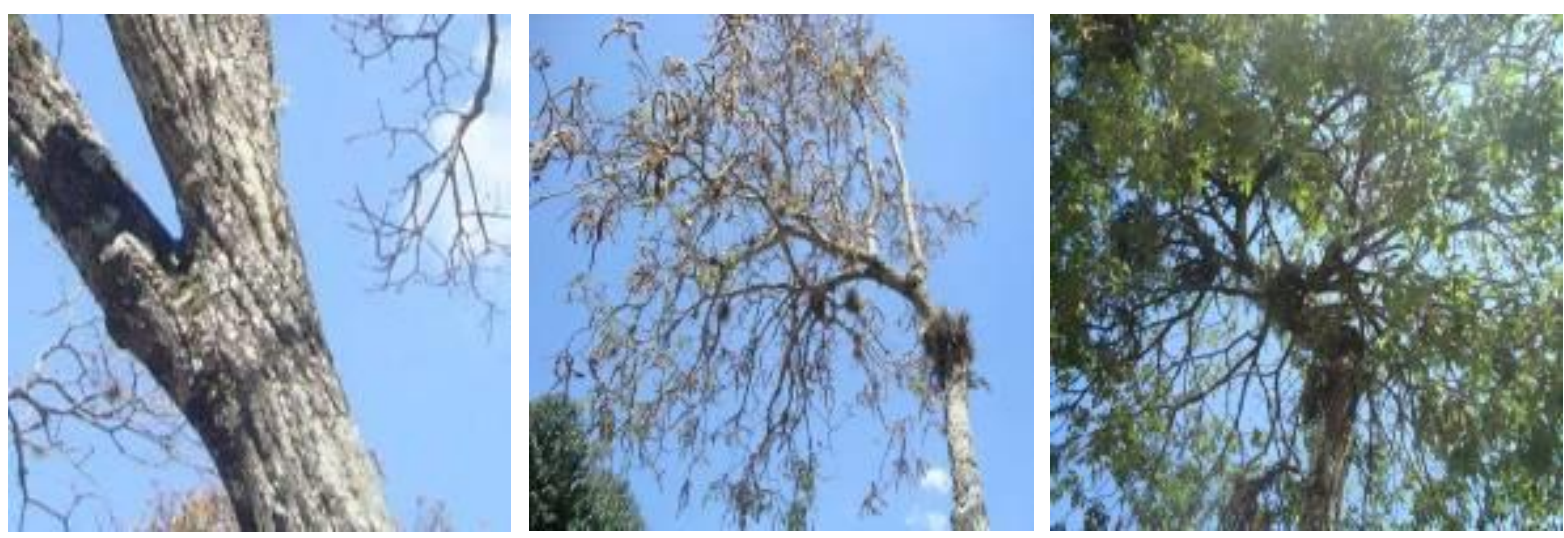


\section{Lafoensia pacari Saint-Hilaire}

O dedaleiro é uma espécie nativa, de grande porte, podendo alcançar 18 metros de altura. Possui hábito perenifólio, porém nas árvores de rua de Curitiba esta espécie possui hábito perenifólio. Sua copa é globosa e densa (Figura 8). A superfície da casca é áspera e a densidade da madeira é de $0,8 \mathrm{~g} / \mathrm{cm}^{3}$ (CARVALHO, 2003; LORENZI,1992).

Figura 8. Detalhe do tronco, hábito e copa

Figure 8. Detail of the trunk, habit and canopy
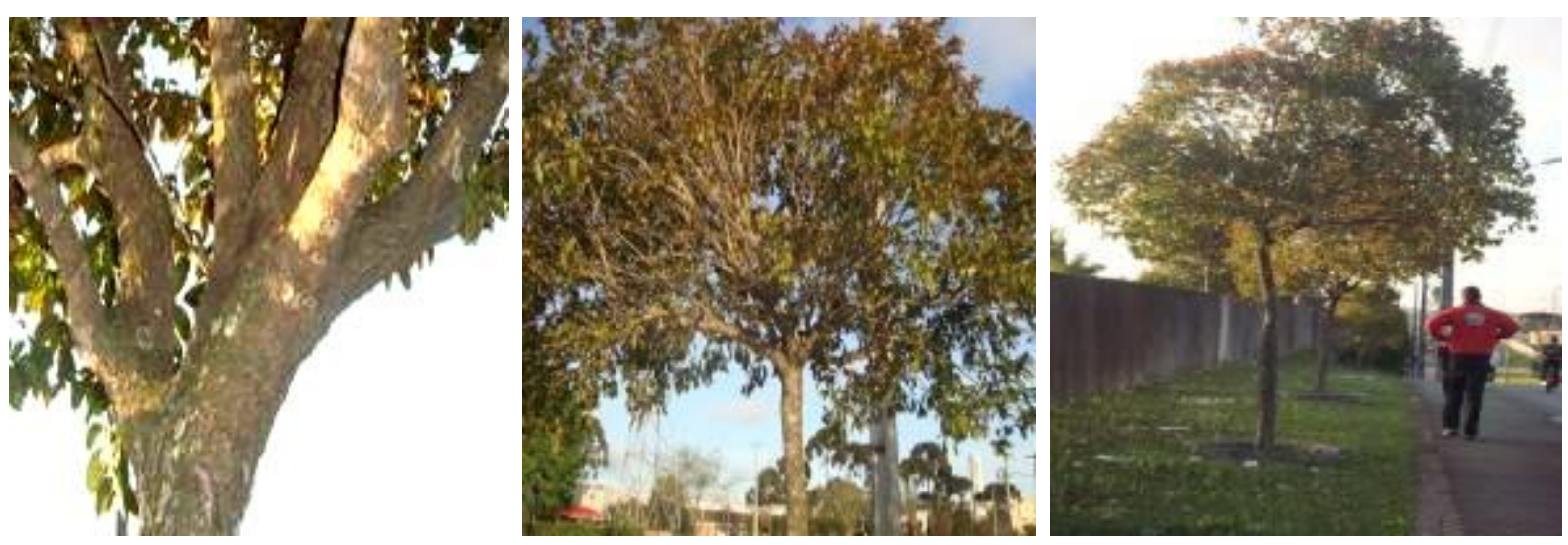

Quadro 1. Características morfológicas das espécies selecionadas

Picture 1. Morphological characteristics of selected species

\begin{tabular}{|c|c|c|c|c|c|}
\hline \multirow{2}{*}{\multicolumn{2}{|c|}{ Características }} & \multicolumn{4}{|c|}{ Espécies } \\
\hline & & Ipê-amarelo- & Dedaleiro & Extremosa & Tipuana \\
\hline \multirow{3}{*}{ Porte da árvore } & Pequeno $<6 \mathrm{~m}$ & & & & \\
\hline & Médio $6-12 \mathrm{~m}$ & $\mathrm{x}$ & & $x$ & \\
\hline & Grande $>12 m$ & & $\mathrm{x}$ & & $\mathrm{x}$ \\
\hline \multicolumn{2}{|c|}{ Densidade da madeira } & $1,05 \mathrm{~g} / \mathrm{cm}^{3}$ & $0,80 \mathrm{~g} / \mathrm{cm}^{3}$ & $0,59 \mathrm{~g} / \mathrm{cm}^{3}$ & $0,63 \mathrm{~g} / \mathrm{cm}^{3}$ \\
\hline \multirow{2}{*}{ Aspecto da casca } & Lisa & & & $\mathrm{x}$ & \\
\hline & Áspera & $x$ & $x$ & & $x$ \\
\hline Forma da copa & Globosa & $x$ & $x$ & $x$ & $x$ \\
\hline \multirow{2}{*}{ Densidade da copa } & Densifoliada & $x$ & $x$ & & $x$ \\
\hline & Aberta & & & $x$ & \\
\hline \multirow{2}{*}{ Procedência } & Nativa & $x$ & $x$ & & \\
\hline & Exótica & & & $x$ & $x$ \\
\hline \multirow{2}{*}{ Hábito } & Decídua & $x$ & & $x$ & $x$ \\
\hline & Semi-decídua & & $\mathrm{x}$ & & \\
\hline
\end{tabular}

Nota: As características morfológicas foram obtidas com base em: Lorenzi (1992, 2000), Lorenzi et al. (2003), Mainieril e Chimelo (1989); Backes e Irgang (2004).; Carvalho $(2003,2006)$ 
Considerando as características das quatro espécies analisadas, 50\% são exóticas; 75\% são de casca áspera; $75 \%$ são caducifólias; $75 \%$ são de copa globosa e densifoliada e $100 \%$ são de médio a grande porte. Observou-se que as características como superfície de casca, hábito, forma e densidade da copa e altura não diferem entre ás árvores susceptíveis ou não ao parasitismo (Quadro 1).

Verificou-se que as árvores infestadas são exóticas, a mesma tendência foi observado por Rotta (2001) analisando a infestação por erva-de-passarinho no Passeio Público de Curitiba, onde $67 \%$ das árvores infestadas são exóticas. White et al. (2010), analisando a ocorrência de erva-de-passarinho na arborização da Universidade Federal de Sergipe, Campus São Cristóvão constatou que a infestação ocorreu em quatro espécies exóticas - Azadirachta indica A. Juss., Casuarina equisetifolia Linn., Pithecellobium dulce (Roxb.) Benth. e Terminalia catappa Linn. - e em apenas uma planta nativa - Anacardium occidentale Linn.

Atualmente ainda não se tem resultados repetitivos em diferentes cidades brasileiras que confirmem que determinadas espécies arbóreas podem ser parasitadas por erva-depassarinho devido ao favorecimento de uma característica morfológica. Segundo Downey (1996), algumas espécies de parasitas são altamente oportunistas e pode parasitar espécies de plantas que nunca tenha encontrado anteriormente.

Nesta pesquisa foi observado que as espécies analisadas com nenhuma infestação possuem densidade da madeira alta a muito alta, possivelmente esta característica atribui ao hospedeiro resistência à penetração haustorial, com tudo, é necessário que se aprofunde os estudos nesta direção, a fim de comprovar tal constatação.

Acredita-se que as características da madeira e casca podem influenciar na maior ou menor susceptibilidade de cada espécie, atribuindo resistência mecânica à penetração haustorial e incompatibilidade química (YAN, 1993; ROTTA, 2001), porém as características morfológicas analisadas neste estudo não se diferenciaram entre as espécies susceptíveis e resistentes a infestação de erva-de-passarinho.

\section{CONCLUSÕES}

Com os resultados obtidos chegaram-se as seguintes conclusões:

a) a característica densidade da madeira pode representar um fator limitante a ocorrência de erva-de-passarinho (hemiparasita), porém há a necessidade de estudos mais aprofundados; 
b) as espécies exóticas apresentaram maior ocorrência de erva-de-passarinho, por esse motivo recomenda-se que sejam plantadas preferencialmente espécies nativas na arborização de ruas de Curitiba.

\section{AGRADECIMENTOS}

Agradeço a Daniela Biondi, pela sua orientação e dedicação, e ao Rogério Bobrowski pela disponibilização dos dados preliminares, tornando possível a realização deste trabalho.

\section{REFERÊNCIAS}

ARRUDA, R. S. Especificidade de hospedeiros por Struthanthusaff. Polyanthus (Loranthaceae) em uma área de cerrado, Uberlândia, Minas Gerais. 2004. $34 \mathrm{f}$. Dissertação (Mestrado em Ecologia e Conservação de Recursos Naturais) - Universidade Federal de Uberlândia, Uberlândia, 2004.

AUKEMA, J. E. Vectors, viscin, and Viscaceae: mistletoes as parasites, mutualists and resources. Frontiers in Ecology and the Environment, Washington, DC, v.1, n.3, p.212 219, 2003.

BACKES, P. \& IRGANG, B. 2004. Árvores cultivadas no Sul do Brasil: Guia de identificação e interesse paisagístico das principais espécies exóticas. $1^{\underline{a}}$ ed. Porto Alegre. Ed. Paisagem do Sul. 204p.

BIONDI, D.; ALTHAUS. M. Árvores de Rua de Curitiba: cultivo e manejo. Curitiba: FUPEF, 2005.182p.

CARVALHO, P. E. R. Espécies Arbóreas Brasileiras. EMBRAPA informação tecnológica, Colombo - PR: Embrapa Florestas, v.1, 1039p; 2003.

Espécies Arbóreas Brasileiras. EMBRAPA informação tecnológica, Colombo - PR: Embrapa Florestas, v.2, 627p; 2006.

CAZETTA, E.; GALETTI, M. Ecologia das ervas-de-passarinho.Ciência Hoje, São Paulo, v.3, n. 94, p.72 - 74, 2003.

DOWNEY, P. O. A regional examination of the mistletoe host species inventory. Cunninghamia 8: 354-361, 1996. 
HARRIS, R. W. Arboriculture: integrated management of landscape trees, shrubs and vines. New Jersey: Prentice-Hall, 1992. 674p.

HEMLINGER, C.; WACHOWICZ, C. M.; BARCIK, C. Infestação de Tripodanthusacutifolius (erva-depassarinho) em três espécies utilizadas na arborização urbana da cidade de Curitiba - Paraná - Brasil. In: CONGRESO LATINOAMERICANO DE BOTANICA, 8., 2002; CONGRESO COLOMBIANO DE BOTANICA, 2., 2002. Libro de resúmenes... Cartagena: Unilibros, 2002. p.173.

IAP. Portaria IAP n074, de 19 de abril de 2007 In:http://www.institutohorus.org.br/downlo ad/marcos_legais/Portaria_IAP_074.pdf. 8p. 2007. Acesso em: 28 de novembro de 2011.

LEAL, L.; BUJOKAS, W. M.; BIONDI, D. Análise da infestação de erva-de-passarinho na arborização de ruas de Curitiba, PR. Revista Floresta, Curitiba, v. 36, n. 3, p. 323-330, 2006.

LIZ - Decreto Municipal no 473/200 de 29 de Março de 2008. Disponível em: http://www.leismunicipais.com.br/legislacao-de-curitiba/636003/decreto-473-2008-curitibapr.html. Acesso em: 28 de novembro de 2011.

LORENZI, Harri. Árvores Brasileiras: manual de identificação e cultivo de plantas arbóreas do Brasil. Nova Odessa, SP: Instituto Plantarum. Vol. 1. 4ํe ed. 368p. 1992.

MAINIERI, C.; CHIMELO, J. P. Fichas de características das madeiras brasileiras. São Paulo: IPT, 1989. 418 p.

MATOS, E. C DO A.; NASCIMENTO JÚNIOR, J. E.; MARIANO, D. L. DA S; MARIANO, OLIVEIRA. A. L. DE; Arborização do Bairro Centro da Cidade de Aracaju, Sergipe, e seus Organismos Associados, REVSBAU, Piracicaba - SP, v.5, n.4, p.22-39, 2010.

OLIVEIRA, F. B.; KAPPEL, R. B. Incidência de erva-de-passarinho na arborização de ruas de Porto Alegre. In: CONGRESSO BRASILEIRO DE ARBORIZAÇÃO URBANA, 3., 1994, São Luís, MA. Anais...São Luís, MA: SBAU, 1994. p.335 - 346.

ROTTA, E. Erva-de-passarinho (Loranthaceae) na arborização urbana: Passeio Público de Curitiba, um estudo de caso.135f. Tese (Doutorado em Engenharia Florestal) - Setor de Ciências Agrárias, Universidade Federal do Paraná, Curitiba, 2001.

RUSCHEL, D.; LEITE, S. L. C. Arborização urbana em uma área da cidade de Lajeado, Rio Grande do Sul, Brasil. Caderno de Pesquisa Série Biologia, Santa Cruz do Sul, v. 14, n. 1, p. 7-24, 2002 
WHITE, B. L. A.; RIBEIRO, A. DE S.; WHITE, L. A. S.; NASCIMENTO JÚNIOR, J. E. DO; Análise da Ocorrência de Erva-De-Passarinho na Arborização da Universidade Federal de Sergipe, Campus São Cristóvão, FLORESTA, Curitiba, PR, v. 41, n. 1, p. 1-8, jan./mar. 2011.

YAN, Z. (1993) Resistance to haustorial development of two mistletoes, Amyemapreissii (Miq.) Tieghem\&Lysianaexocarpi (Behr.) Tieghemssp. exocarpi (Loranthaceae), on host and nonhost species. InternationalJournalofPlantSciences 154: 386-394.

ZILIOTTO, M. A.; SEITZ, R. A.; MIELKE, E.; SALGUEIRO, R. L. Experiências práticas na condução do controle de ervas-de-passarinho de diferentes espécies na arborização de Curitiba (PR). In: ENCONTRO NACIONAL DE ARBORIZAÇÃO URBANA, 8., 1999, Fortaleza. Anais... Fortaleza: SBAU, 1999. p.76- 78. 